\title{
SISAL FIBRE CONCRETE AND ITS PROSPECTIVE
}

A P PLICATIONS

By: A.S. Mawenya*

\section{Introduction}

Concrete is a very viable and widely used construction material that is characterized by a high compressive strength and superior durability, However, plain concrete has the disadvantage that it is brittle and weak in tension, its tensile strength being only about $10 \%$ of its compressive strength. This makes it unsuitable for the manufacture of elements which carry tensile stresses such as beam and pla te elements.

The most common way of compensating for the low tensile strength of concrete is the use of reinforcing steel bars which by bonding to the concrete matrix carry the tensile stresses. Another approach is to mix the concrete with thin short fibres of steel or other suitable reinforcing material. The fibres then act in unison with the concrete to form a tougher material which is more energy-absorbing and having improved tensile strength.

\section{Fibre Reinforced Materials}

The idea of reinforcing brittle materials with thin fibres is not new. Perhaps the earliest applications can be found in Africa where straw-reinforced mud and clay have been commonly used in the past for building purposes, Current applications of fibre reinforcement have concentrated on the use of modern-high strength steel, asbestos, glass and plastics fibre. Examples of these are: - Ferrocement, where the cement based matrix is reinforced with
steel fibres (1)

- Asbestos cement, where asbestos fibres are used to reinforce the cement based matrix

- Glass fibres reinforced cement, consisting of cement based matrix reinforced with glass fibres (2)

- Carricrete, a concrete product which is mixed with polypropylene plastics fibres. (3)

Unfortunately the applications sited above have produced high quality materials which are relatively expensive in relation to their strength. It has therefore been found worthwhile to explore the possibility of using sisal fibres as an alternative because they can yield cheaper types of fibrous concrete than can be achieved with steel or synthetic fibres. The idea of using sisal fibres as reinforcement for concrete is quite attractive and of particular interest to the Tanzanian situation where sisal is abundant and cheap in comparison with steel. The tensile strength of sisal fibre is of the same order of magnitude as that of steel $\left(600-800 \mathrm{~N} / \mathrm{mm}^{2}\right)(4)$. However, its modulus of elasticity is low (about $27 \mathrm{kN} / \mathrm{mm}^{2}$ ). Experimental data also indicate that the fibres are linear elastic and do not exhibit any appreciable creep under load. The elongation at breaking is between $2-4 \%$. Sisal-sibres, like other vegetable fibres, may have problems from fungus attack and sensitivity to insect attack, but these problems are minimal if the processing of the fibres is carefully handled. *Associate Professor, Civil Engineering Department, University of
Dar es Salaam. 


\section{Sisal Fibre Conćrete $(3,6,7)$}

In sisal fibre concrete, sisal fibres are used to reinforce tne cuntete matrix. In order to achieve the best results, the concrete matrix should be of rather high quality with small maximum aggregate size (upto $2 \mathrm{~mm}$ ). The quality of.the.concrete matrix is mainly dependent on the cement content and aggregate grading. Ordinary Portland cement can be used with ordinary sand-cement mortars. These are mixed with water to a rather wet mix of appropriate consistency and workability.

The sisal fibres can be used as chopped short fibres (15-50 mm in length) or as continuous long fibres (upto $1500 \mathrm{~mm}$ long). When mixed with the concrete matrix short fibres become randomly oriented in the concrete, while long fibres can be.aligned to correspond with the optimum direction for carrying tensile stresses.

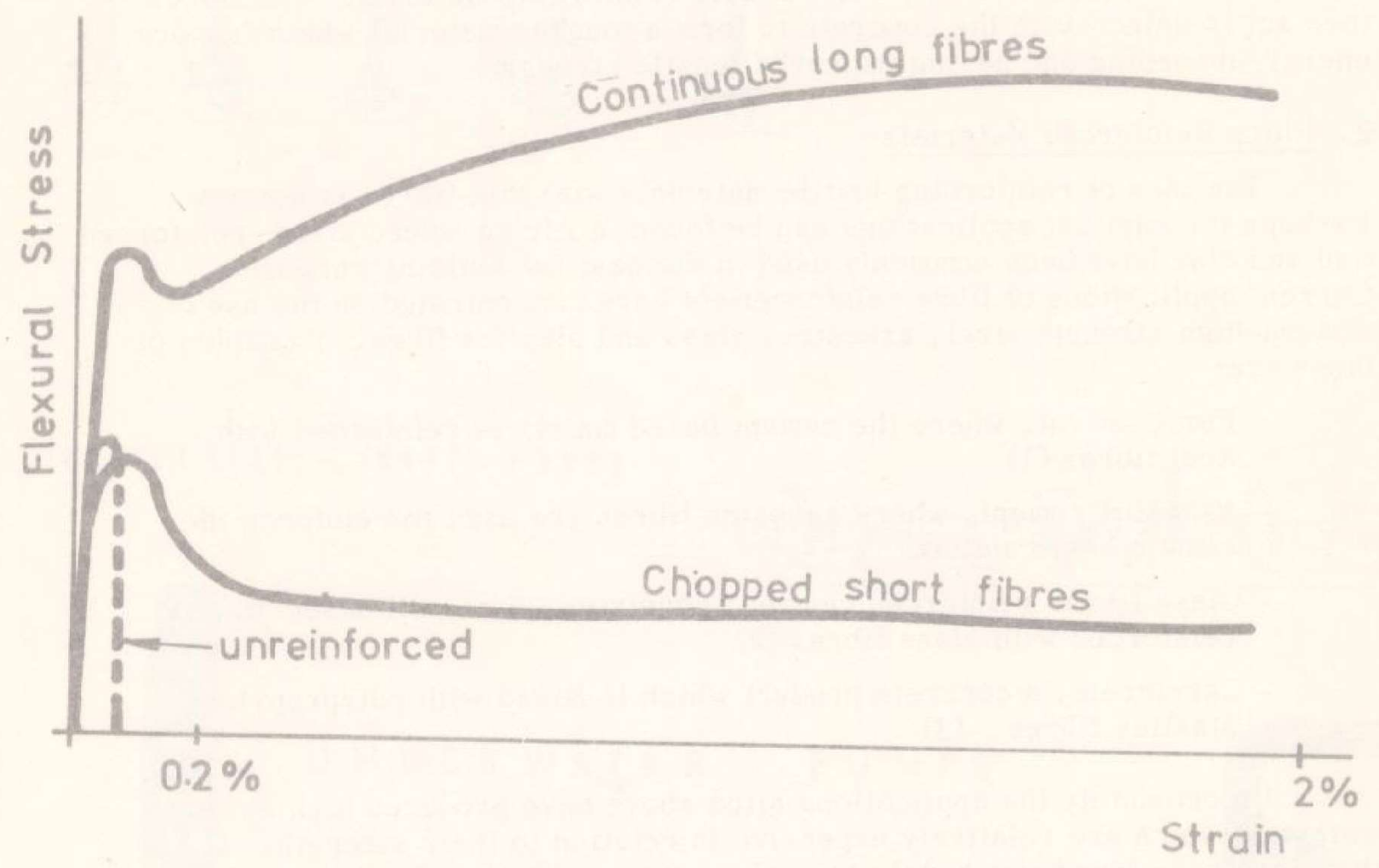

Fig. 1. Typical load-deformation curves for concrete beams with different types of sisal fibres.

The reinforcement of a concrete beam with sisal fibres changes the load deformation behaviour of the beam as indicated in Figure 1 above. In the case of the beam reinforced with short fibres there is normally very little improvement in the ultimate load carrying capacity deformation. When continuous fibres are used a very pronounced strengthening effect is obtained. The ultimate load carrying capacity is nearly doubled and the beam also exhibits considerable plastic behaviour. By examining the areas under the load-deformation characteristics it is also evident that the energy absorbing capacity i.e. the toughness of sisal fibre concrete is more than thatof plain unreinforced concrete. This superior toughness of sisal fibre concrete coupled with its improved flexural strength and deformability makes it an attractive material for certain semi-structural and non-structural applications. 
4. Possible Applications of Sisal Fibre Concrete

4.1 Roofing Sheets. There are not many alternarives for roofing materials in Tanzania, especially in the rural areas where modern housing has to rely almost exclusively on the use of corrugated iron or aluminium sheets for roofing to be the single most expensive item in rural housing schemes. Current developments which are being undertaken at the Building Research Unit (6) show that roofing sheets make from sirsal fibre concrete can provide a cheap alternative to the conventional corrugated iron sheets. Sisal fibre concrete sheets are fire resistant and durable. They also have good thermal and sound insulating properties.

4.2 Light Walling and Cladding. Sun screens and cladding for multistorey buildings can be manufactured from sisal fibre concrete sheets, while sisal fibre concrete blocks can be used for making light load bearing wall elements.

4.3 Plastering. Sisal fibre concrete surfacing can protect walls made of mud and pole construction from destruction by rain.

4.4 Other applications. Sisal fibre concrete can also be used for the manufacture of paving slabs where full advantage can be taken of its high strength and toughness. There are also iwide possibilities for semi-structural applications of sisal fibre concrete in the form of small light beams, light frames and trusses, and as permanent formwork for cast in-situ concrete.

5. References

1. LANKARD, D.R. and DICKERSON, R.F. Fibre-reinforced WIRAND concrete - a new construction material. Cement and Betung, 1971:74 pp 509-515.

2., GRC - Glass fibre reinforced cement, Building Research Establishment. Digest D216: 1978.

3. concrete 1972 : 9 pp 533-536.

4. LOCK, G.W. , Sisal, Longman Green \& Co. Limited 1962.

5. NILSSON, L. Reinforcement of concrete with sisal and other vegetable fibres. Swedish Council for Building Research, Document D14 : 1975.

6. PERSSON, H. and SKARENDAHL, A. Sisal fibre concrete for roofing sheets and other purposes. Swedish International Development Authority, 1978.

7. MWAMILA. B.L.M. Properties and applications of sisal reinforced concrete. M.Sc, research project, UDSM. (on-going). 